\title{
Avaliação morfológica e produção de minijardim clonal de Eucalyptus benthamii em relação a $\mathrm{Zn}$ e B
}

\author{
Gilvano Ebling Brondani ${ }^{1}$, Francisco José Benedini Baccarin ${ }^{1}$, Heron Wilhelmus de Wit Ondas ${ }^{1}$, Antônio Natal Gonçalves ${ }^{1}$ \\ Marcílio de Almeida ${ }^{1}$
}

${ }^{1}$ Universidade de São Paulo, Escola Superior de Agricultura "Luiz de Queiroz", CEP 13.418-900, Piracicaba, SP, Brasil

*Autor correspondente:
gebrondani@yahoo.com.br
Termos para indexação:
Solução nutritiva
Miniestaquia
Nutrição mineral
Fertirrigação
Index terms:
Nutritive solution
Mini-cutting technique
Mineral nutrition
Fertigation

Histórico do artigo:

Recebido em 27/02/2012

Aprovado em 28/05/2012

Publicado em 29/06/2012

doi: $10.4336 / 2012 . p f b .32 .70 .35$
Resumo - Objetivou-se avaliar a sobrevivência de minicepas e a produção de miniestacas de Eucalyptus benthamii em relação a diferentes concentrações de Zn e $\mathrm{B}$ ao longo de sucessivas coletas de brotos. Os brotos foram oriundos de minicepas (clones BP101, BP118 e BP120) fertirrigadas com soluções nutritivas variando nas concentrações de $\mathrm{Zn}$ e B ( $\mathrm{S} 1$ - isento de $\mathrm{Zn}$ e B, S2 - 0,5 $\mathrm{mg} \mathrm{L}^{-1}$ de $\mathrm{Zn}, \mathrm{S} 3$ - 0,5 mg L-1 de B, S4 - 0,5 mg L ${ }^{-1}$ de Zn e B, S5 - 1,0 mg L $\mathrm{m}^{-1}$ de Zn e B, S6 - 2,0 mg L ${ }^{-1}$ de Zn e B), sendo realizadas oito coletas de brotos no minijardim clonal. Ao longo do experimento foram avaliadas a sobrevivência das minicepas, a produção de miniestaca, número de folhas, número de nós, comprimento de brotos, intervalo de entrenós e aparência visual das minicepas, visando identificar sintomas de deficiência ou toxidez nutricional. A sobrevivência das minicepas, produção de miniestacas, número de folhas, número de nós, comprimento de brotos e intervalo de entrenós variaram significativamente em relação aos tratamentos avaliados, sendo que as soluções S5 e S6 apresentaram as melhores respostas.

\section{Morphological and production evaluation of Eucalyptus benthamii clonal mini-garden regarding to $\mathrm{Zn}$ and $\mathrm{B}$}

\begin{abstract}
bstract - The aim of this study was to evaluate the mini-stumps survival and the minicuttings production of Eucalyptus benthamii regarding to $\mathrm{Zn}$ and B concentrations during successive collection of shoots. Shoots were collected from mini-stumps (BP101, BP118 and BP120 clones) fertigated with nutrient solutions containing different concentrations of $\mathrm{Zn}$ and $\mathrm{B}$ (S1 - free of $\mathrm{Zn}$ and B, S2 - $0.5 \mathrm{mg} \mathrm{L}^{-1} \mathrm{Zn}, \mathrm{S} 3-0.5 \mathrm{mg} \mathrm{L} \mathrm{L}^{-1} \mathrm{~B}, \mathrm{~S} 4-0.5 \mathrm{mg} \mathrm{L}^{-1}$ $\mathrm{Zn}$ and B, S5 - $1.0 \mathrm{mg} \mathrm{L}^{-1} \mathrm{Zn}$ and B, S6 - $2.0 \mathrm{mg} \mathrm{L}^{-1} \mathrm{Zn}$ and B). Eight shoot collections of the clonal mini-garden were performed. The mini-stumps survival, mini-cuttings production, leaves number, nodes number, shoots length, internodes interval and visual appearance of mini-stumps to identify symptoms of nutritional deficiency or toxicity were evaluated. The mini-stumps survival, mini-cuttings production, leaves number, nodes number, shoots length and internodes interval varied significantly among to treatments, and the nutritive solutions S5 and S6 presented the best responses.
\end{abstract}

\section{Introdução}

A clonagem de espécies de Eucalyptus em escala comercial no Brasil já é realidade, seja ela realizada pela técnica de estaquia, miniestaquia ou por micropropagação. Atualmente, a técnica de miniestaquia é a mais difundida entre as grandes empresas florestais, sendo responsável pela produção de milhares de mudas para o abastecimento do setor. A micropropagação é utilizada em casos específicos, principalmente para promover o rejuvenescimento dos clones selecionados e produzir mudas para serem 
utilizadas como microcepas em sistemas de microjardins clonais. A estaquia geralmente é utilizada para o resgate de matrizes adultas, e devido aos baixos índices de enraizamento, ao ser comparada com as demais técnicas de propagação (Alfenas et al., 2004), não é emprega em escala comercial.

Apesar de todos os avanços proporcionados pela pesquisa na área de biotecnologia florestal, alguns problemas ainda persistem em termos de clonagem de Eucalyptus, principalmente ao se considerar as espécies destinadas ao plantio em regiões mais frias. Eucalyptus benthamii é uma espécie considerada de clima subtropical (Assis \& Mafia, 2007; Jovanovic \& Booth, 2002; Mujiu et al., 2003; Paludzyszyn Filho et al., 2006) que apresenta problemas na fase de rizogênese em propágulos (Brondani et al., 2010a; Graça et al., 1999; Wit Ondas et al., 2009) ao ser comparado com as demais espécies de Eucalyptus destinadas ao plantio em regiões tropicais (Assis \& Mafia, 2007), o que pode comprometer a produção de mudas de genótipos selecionados. Contudo, alguns progressos podem ser alcançados com o ajuste do manejo do minijardim clonal em termos de nutrição (Eldridge et al., 1994; Hartmann et al., 2011), o que pode proporcionar a produção de propágulos com maior predisposição ao enraizamento (Alfenas et al., 2004; Higashi et al., 2005).

A base do minijardim clonal é composta pelo conjunto de minicepas (Alfenas et al., 2004), sendo que a rizogênese em propágulos está intimamente ligada ao seu estado fisiológico (Higashi et al., 2005). Inúmeros trabalhos relatam que a sobrevivência de minicepas varia com o tempo de cultivo (Wendling \& Xavier, 2005; Almeida et al., 2007; Brondani et al., 2010b; Brondani et al., 2010c), com a nutrição (Cunha et al., 2005; Higashi et al., 2005; Rosa et al., 2009), temperatura (Alfenas et al., 2004), sazonalidade (Brondani, 2008; Cunha et al., 2009) e com as condições de manejo adotado durante a coleta de brotos (Titon et al., 2003), as quais podem interferir significativamente na produção (Alfenas et al., 2004). De acordo com Higashi et al. (2005), geralmente as minicepas de Eucalyptus apresentam adequada longevidade para suprir a produção de brotos por longos períodos, sendo essas substituídas durante a observação da queda repentina da produção de brotos (Alfenas et al., 2004), aumento da mortalidade (Assis \& Mafia, 2007) e pelo ataque de pragas e doenças associadas ou não a alterações fisiológicas, como deficiências nutricionais (Higashi et al., 2005; Silveira et al., 1998).
Os micronutrientes $\mathrm{Zn}$ e $\mathrm{B}$, devido as suas funções fisiológicas (Sakya et al., 2002; Epstein \& Bloom, 2004; Rubio et al., 2009; Taiz \& Zeiger, 2009) são considerados importantes componentes da solução nutritiva para garantir a produção de brotos com qualidade e quantidade suficientes para serem usados na miniestaquia. As concentrações desses micronutrientes na solução nutritiva variam de acordo com as condições de manejo para cada genótipo de interesse, contudo não existe relato de suas variações na fertirrigação de minicepas de Eucalyptus benthamii, bem como, sobre os efeitos morfofisiológicos na produção de brotos.

Em termos de crescimento e desenvolvimento da planta destacam-se os hormônios vegetais (Taiz \& Zeiger, 2009) e, dentre as diversas classes, as auxinas desempenham papéis importantes no ciclo vegetativo, além de estarem intimamente relacionadas ao enraizamento de propágulos (Ludwig-Müller, 2000; Müller \& Weiler, 2000; Pollmann et al., 2009; Kratz et al., 2010). O triptofano é um aminoácido comum em plantas que é considerado um precursor de AIA (Müller et al., 2002; Pollmann et al., 2009), sendo que o Zn é essencial para a sua síntese (Malta et al., 2002; Ishihara et al., 2007; Souza \& Pereira, 2007). Dessa forma, o suprimento adequado de nutrientes no minijardim clonal por meio da fertirrigação poderá influenciar os teores endógenos de auxinas e triptofano, favorecendo a qualidade do broto emitido e sua predisposição ao enraizamento.

O presente trabalho objetivou quantificar a produção de miniestacas e a sobrevivência de minicepas em relação às coletas de brotos, concentrações de $\mathrm{Zn}$ e B e variabilidade do material genético.

\section{Material e métodos}

\section{Constituição do minijardim clonal}

Mudas clonais identificadas como BP101, BP118 e BP120 dos genótipos superiores de Eucalyptus benthamii Maiden \& Cambage foram utilizadas para a instalação dos experimentos. As plantas matrizes foram provenientes de teste de progênies com dois anos e seis meses de idade, o qual foi estabelecido no espaçamento 2,0 m x 3,0 m em Concórdia, SC. O lote de sementes foi adquiro da população base genética de Eucalyptus benthamii da Embrapa Florestas, Colombo, PR.

As unidades experimentais foram compostas por mudas clonais propagadas pelo processo de 
miniestaquia com aplicação de $2.000 \mathrm{mg} \mathrm{L}^{-1}$ de AIB (enraizamento em casa de vegetação durante 42 dias) e cultivadas em vasos plásticos (18 x $16 \times 45 \mathrm{~cm})$ com duas aberturas na porção inferior. $\mathrm{O}$ substrato foi composto por areia, fração fina $(0,10 \mathrm{~mm}<$ diâmetro de partícula $<0,25 \mathrm{~mm}$ ), o qual foi peneirado (peneira de malha $3 \mathrm{~mm}$ ), lavado com água deionizada por cinco vezes e autoclavado durante 20 minutos a $121{ }^{\circ} \mathrm{C}$ $\left(\approx 1,0 \mathrm{kgf} \mathrm{cm}^{-2}\right)$, a fim de erradicar plantas daninhas e patógenos, como fungos e bactérias. Previamente ao plantio das mudas nos vasos, procedeu-se a lavagem do sistema radicial das mudas com água deionizada durante 10 minutos, com a finalidade de lixiviar nutrientes e demais componentes aderidos.

Os vasos foram suspensos por grades metálicas a $85 \mathrm{~cm}$ do solo, sendo plantadas seis mudas por vaso no espaçamento $10 \mathrm{~cm} \times 8 \mathrm{~cm}$, os quais foram compostos por duas mudas de cada clone dispostas sequencialmente. Após sete dias efetuou-se a quebra do caule das mudas a $10 \mathrm{~cm}$ acima da porção basal, com a finalidade de reduzir a dominância apical e favorecer o crescimento de brotos axilares, os quais foram emitidos aos 21 dias após a quebra do caule. Para a formação das minicepas, foi realizada poda da parte aérea a $7 \mathrm{~cm}$ acima da base da muda, aos 15 dias após a quebra do caule, conforme metodologia descrita por Brondani (2008), constituindo o minijardim clonal em sistema de vaso.

\section{Manejo das minicepas}

O minijardim clonal foi instalado em condições de casa de vegetação recoberta com polietileno transparente e composta por dois sistemas de ventiladores, sendo a estrutura pertencente ao Laboratório de Fisiologia das Árvores do Departamento de Ciências Florestais da Escola Superior de Agricultura "Luiz de Queiroz", Universidade de São Paulo.

Os dados da temperatura do ar foram coletados diariamente, entre novembro de 2009 a outubro de 2010. A cada sete dias adicionou-se $100 \mathrm{~mL}$ de solução nutritiva básica por minicepa (Tabela 1), sendo realizada irrigação com água deionizada diariamente, visando suprir a perda excessiva por evapotranspiração. A cada semana foi realizada lavagem da areia com água deionizada para evitar o excesso de salinização.

Tabela 1. Composição da solução nutritiva básica para a fertirrigação do minijardim clonal de Eucalyptus benthamii.

\begin{tabular}{|c|c|c|c|c|c|}
\hline Nutriente & $\begin{array}{c}\text { Solução } \\
\text { Nutritiva* }^{*} \\
\left(\mathrm{mg} \mathrm{L}^{-1}\right)\end{array}$ & Fonte de Macro e Micronutriente & FQ & $\mathbf{P M}$ & $\left(\mathrm{mg} \mathrm{L}^{-1}\right)$ \\
\hline $\mathrm{N}-\mathrm{NO}_{3}^{-}$ & 60,00 & Nitrato de potássio $\left(\right.$ Nuclear $\left.^{\circledR}\right)$ & $\mathrm{KNO}_{3}$ & 101,10 & 206,85 \\
\hline $\mathrm{N}-\mathrm{NH}_{4}^{+}$ & 30,00 & Monoamônio fostato (Mallinckrodt ${ }^{\mathbb{R}}$ ) & $\mathrm{NH}_{4} \mathrm{H}_{2} \mathrm{PO}_{4}$ & 115,03 & 44,57 \\
\hline $\mathrm{P}$ & 12,00 & Nitrato de amônio $\left(\right.$ Reagex $\left.^{\circledR}\right)$ & $\mathrm{NH}_{4} \mathrm{NO}_{3}$ & 80,04 & 140,50 \\
\hline $\mathrm{Ca}$ & 40,00 & Cloreto de cálcio $\left(\right.$ Synth $\left.^{\circledR}\right)$ & $\mathrm{CaCl}_{2} \cdot 2 \mathrm{H}_{2} \mathrm{O}$ & 147,02 & 111,13 \\
\hline $\mathrm{K}$ & 80,00 & Nitrato de cálcio $\left(\right.$ Labsynth $\left.^{\circledR}\right)$ & $\mathrm{Ca}\left(\mathrm{NO}_{3}\right)_{2} \cdot 4 \mathrm{H}_{2} \mathrm{O}$ & 236,15 & 57,18 \\
\hline $\mathrm{S}$ & 10,00 & Cloreto de magnésio $\left(\right.$ Synth $\left.^{\circledR}\right)$ & $\mathrm{MgCl}_{2} \cdot 6 \mathrm{H}_{2} \mathrm{O}$ & 203,30 & 50,46 \\
\hline $\mathrm{Mg}$ & 12,00 & Sulfato de magnésio (Mallinckrodt ${ }^{\mathbb{R}}$ ) & $\mathrm{MgSO}_{4} \cdot 7 \mathrm{H}_{2} \mathrm{O}$ & 246,48 & 60,49 \\
\hline $\mathrm{Cu}$ & 0,10 & Sulfato de manganês $\left(\right.$ Ecibra $\left.^{\circledR}\right)$ & $\mathrm{MnSO}_{4} \cdot \mathrm{H}_{2} \mathrm{O}$ & 169,01 & 4,9223 \\
\hline $\mathrm{Fe}$ & 2,00 & Sulfato de cobre (Mallinckrodt ${ }^{\circledR}$ ) & $\mathrm{CuSO}_{4} .5 \mathrm{H}_{2} \mathrm{O}$ & 249,68 & 0,3929 \\
\hline Mo & 0,02 & Sulfato de ferro $\left(\right.$ Synth $\left.^{\circledR}\right)$ & $\mathrm{FeSO}_{4} \cdot 7 \mathrm{H}_{2} \mathrm{O}$ & 278,02 & 9,9520 \\
\hline \multirow[t]{2}{*}{$\mathrm{Mn}$} & 1,60 & Sódio - EDTA (Nuclear ${ }^{\mathbb{R}}$ ) & $\mathrm{Na}_{2}$-EDTA. $2 \mathrm{H}_{2} \mathrm{O}$ & 372,24 & 13,3110 \\
\hline & & Molibdato de sódio $\left(\operatorname{Merck}^{\circledR}\right)$ & $\mathrm{Na}_{2} \mathrm{MoO}_{4} \cdot 2 \mathrm{H}_{2} \mathrm{O}$ & 241,95 & 0,0504 \\
\hline
\end{tabular}

\footnotetext{
${ }^{*} \mathrm{O}$ pH foi ajustado para 6,2 a $25^{\circ} \mathrm{C}$ com ácido clorídrico $(\mathrm{HCl})$ ou hidróxido de sódio $(\mathrm{NaOH})$, ambos a $1 \mathrm{M}$. $\mathrm{FQ}=$ fórmula química, $\mathrm{PM}=$ peso molecular.
} 


\section{Tratamentos e delineamento experimental}

Para avaliação da sobrevivência de minicepas e da produtividade de miniestacas foi monitorado o crescimento e desenvolvimento das minicepas ao longo de sucessivas coletas de brotos. Como tratamentos foram aplicadas diferentes concentrações de zinco (Zn) e boro (B), os quais foram fornecidos por meio de solução nutritiva (Tabela 2).

Tabela 2. Combinação das concentrações de Zn e B para a composição das soluções nutritivas.

\begin{tabular}{ccc}
\hline Solução Nutritiva & $\begin{array}{c}\mathbf{Z n}^{(\mathbf{1})} \\
\left(\mathbf{m g ~ L}^{-1}\right)\end{array}$ & $\begin{array}{c}\mathbf{B}^{(2)} \\
\left(\mathbf{~ m g ~ L}^{-1}\right)\end{array}$ \\
\hline S1 & 0,00 & 0,00 \\
S2 & 0,50 & 0,00 \\
S3 & 0,00 & 0,50 \\
S4 & 0,50 & 0,50 \\
S5 & 1,00 & 1,00 \\
S6 & 2,00 & 2,00 \\
\hline
\end{tabular}

(1) Fornecido na forma de sulfato de zinco (Mallinckrodt ${ }^{\circledR} / \mathrm{ZnSO}_{4} \cdot 7 \mathrm{H}_{2} \mathrm{O} /$ 287,54). ${ }^{(2)}$ Fornecido na forma de ácido bórico $\left(\right.$ Ecibra $\left.^{\circledR} / \mathrm{H}_{3} \mathrm{BO}_{3} / 61,83\right)$.

$\mathrm{O}$ experimento foi conduzido em delineamento em blocos completos ao acaso, em arranjo fatorial $(3 \times 8 \times 6)$ com parcelas subdividas no tempo, sendo os fatores constituídos por três clones (BP101, BP118 e BP120), oito coletas de brotos e seis combinações de Zn e B (Tabela 2), com cinco blocos contendo duas minicepas por parcela.

A cada sete dias adicionou-se $100 \mathrm{~mL}$ da solução nutritiva (Tabelas 1 e 2) por minicepa. $\mathrm{O}$ experimento foi conduzido durante 12 meses, sendo realizadas coletas sucessivas de brotos com intervalos variando de 21 a 35 dias. Ao longo do experimento foram avaliadas a sobrevivência das minicepas (SOB), o número de miniestaca por metro quadrado ao ano (NM), comprimento de broto $(\mathrm{CB})$, número de folhas $(\mathrm{NF})$, número de nós $(\mathrm{NN})$, intervalo de entrenós (IN) e aparência visual das minicepas, visando identificar sintomas de deficiência ou toxidez nutricional (Dell et al., 1995).

$\mathrm{O}$ número de miniestacas por metro quadrado ao ano foi calculado a partir da seguinte fórmula:

$$
N M=\frac{N M I \cdot D A}{I C \cdot A E}
$$

Onde:

$\mathrm{NM}=$ número de miniestaca por metro quadrado ao ano $\left(\right.$ miniestaca $\mathrm{m}^{-2}$ ano $\left.^{-1}\right)$;
NMI = número de miniestaca por minicepa;

$\mathrm{DA}=$ total de dias do ano (considerou-se 365 dias);

IC = intervalo em dias entre cada coleta de brotos;

$\mathrm{AE}=$ área efetiva de cada minicepa (determinado pelo espaçamento do plantio das minicepas no vaso, o qual foi $10 \mathrm{~cm} \times 8 \mathrm{~cm}$, correspondendo a $0,008 \mathrm{~m}^{-2}$ ).

\section{Análise estatística dos dados}

Os dados mensurados de todos os experimentos foram submetidos aos testes de Hartley $(p<0,05)$ e Lilliefors $(p<0,05)$ e transformados quando necessário. Em seguida, foi realizada análise de variância (ANOVA, $p<0,01$ e $p<0,05$ ). De acordo com a significância da ANOVA, os dados dos fatores qualitativos foram comparados pelo teste de Tukey $(p<0,05)$. Realizou-se análise de correlação de Pearson $(p<0,01$ e $p<0,05)$ dos dados ambientais com as variáveis mensuradas.

\section{Resultados}

A sobrevivência de minicepas apresentou valores elevados (superiores a 95\%) até a $7^{\text {a }}$ coleta de brotos, não sendo verificada diferença significativa ao considerar a $1^{\text {a }}$ coleta de brotos até a $7^{\text {a }}$ coleta. Apenas na $8^{\text {a }}$ coleta de brotos foi constatada redução significativa da porcentagem de sobrevivência das minicepas, independente do clone avaliado. Contudo, ainda na $8^{\mathrm{a}}$ coleta de brotos, os valores da porcentagem de sobrevivência das minicepas foram superiores a 91\% (Figura 1), não inviabilizando o seu cultivo para a produção de brotos.

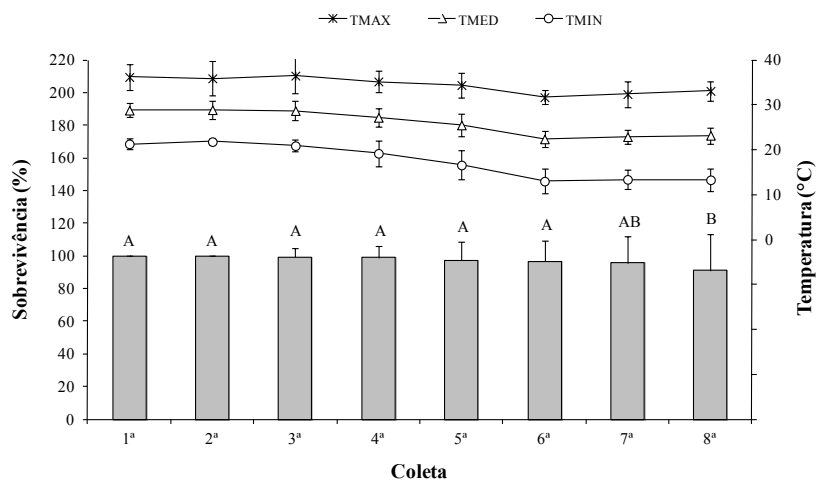

Figura 1. Valores médios da sobrevivência de minicepas de Eucalyptus benthamii em relação à coleta de brotos. Médias seguidas por mesma letra não diferem significativamente pelo teste de Tukey ao nível de 5\% de probabilidade de erro. Dados apresentados como: média \pm desvio padrão. 
Aoanalisara sobrevivência deminicepas em relação aoclone e solução nutritiva na coleta final ( $8^{\mathrm{a}}$ coleta de brotos), pode-se observar que o clone BP118 não variou significativamente em relaçãoà solução nutritiva, apresentando elevada porcentagem de sobrevivência de minicepas (Figura 2). Contudo, os clones BP101 e BP120, apresentaram diferença significativa da sobrevivência de minicepas em relação à solução nutritiva.
Para ambos os clones, as soluções S5 e S6 apresentaram as maiores porcentagens de sobrevivência de minicepas, com valores superiores a $91 \%$. O menor valor da porcentagem de sobrevivência foi registrado para as minicepas fertirrigadas com as soluções S1 e S2 (isentas de B), as quais diferiram significativamente das soluções S3, S4, S5 e S6 para ambos os clones (Figura 2).

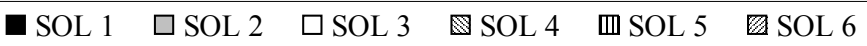

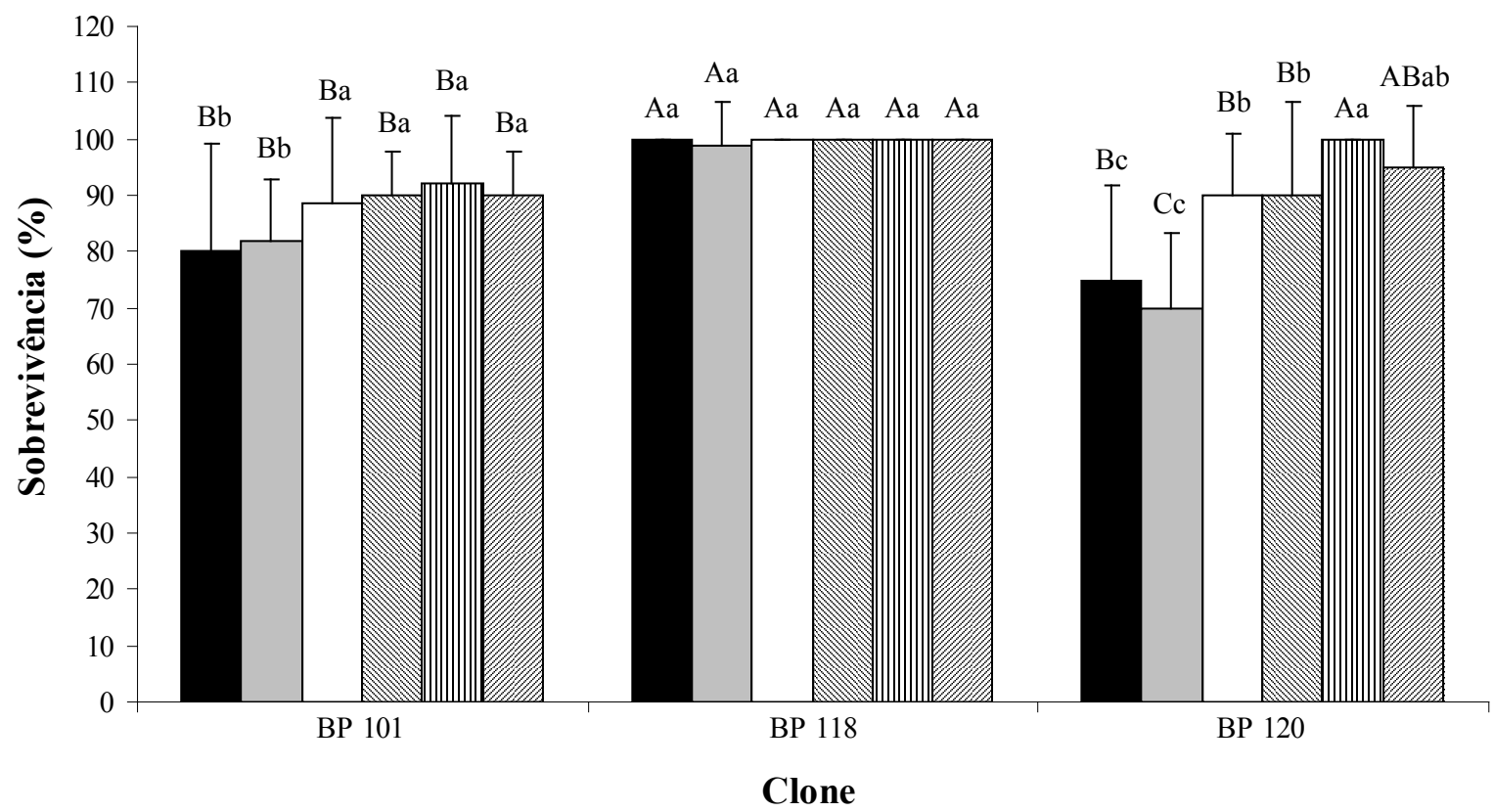

Figura 2. Valores médios para a sobrevivência de minicepas de Eucalyptus benthamii em relação ao clone e solução nutritiva na $8^{\mathrm{a}}$ coleta de brotos. Médias seguidas por mesma letra maiúscula para a mesma solução nutritiva entre os clones e, médias seguidas por mesma letra minúscula para o mesmo clone entre as soluções nutritivas não diferem significativamente pelo teste de Tukey ao nível de $5 \%$ de probabilidade de erro. Dados apresentados como: média \pm desvio padrão.

A qualidade dos brotos coletados (ou seja, comprimento de broto, número de folhas e de nós, e intervalo de entrenós) variou significativamente ao longo das coletas de brotos. Os maiores valores de comprimento de broto foram mensurados na $5^{\mathrm{a}}, 7^{\mathrm{a}}$ e $8^{\mathrm{a}}$ coletas, as quais não diferiram significativamente. As $3^{\mathrm{a}}$ e $4^{\mathrm{a}}$ coletas de brotos apresentaram os menores valores do comprimento de broto (Figura 3). Em termos gerais, o comprimento de broto variou de $5,73 \mathrm{~cm}$ a $8,39 \mathrm{~cm}$, sendo adequados para a confecção de miniestacas.

O número de folhas por broto (Figura 4) e o número de nós por broto (Figura 5) não variaram significativamente em relação à solução nutritiva ao considerar a mesma coleta de broto. Porém, essas características de crescimento variaram significativamente ao longo das coletas de brotos (Figura 4 e Figura 5).



Figura 3. Valores médios para o comprimento de broto (CB) de minicepas de Eucalyptus benthamii em relação à coleta de brotos. Médias seguidas por mesma letra não diferem significativamente pelo teste de Tukey ao nível de $5 \%$ de probabilidade de erro. Dados apresentados como: média \pm desvio padrão. 


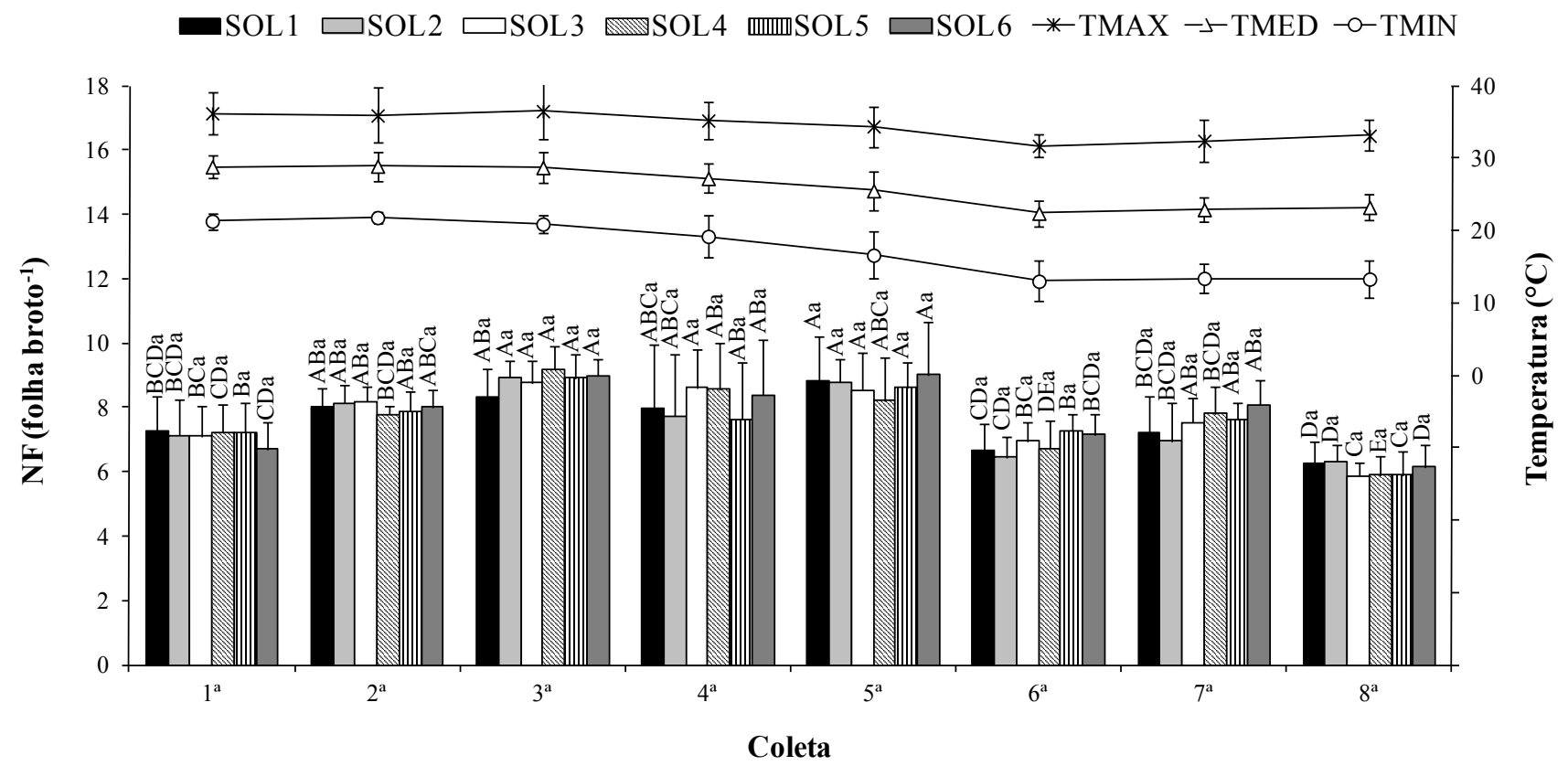

Figura 4. Valores médios do número de folhas por broto (NF) de minicepas de Eucalyptus benthamii em relação a coleta de brotos e solução nutritiva. Médias seguidas por mesma letra maiúscula para a mesma solução nutritiva entre as coletas de brotos e, médias seguidas por mesma letra minúscula para a mesma coleta de brotos entre as soluções nutritivas não diferem significativamente pelo teste de Tukey ao nível de $5 \%$ de probabilidade de erro. Dados apresentados como: média \pm desvio

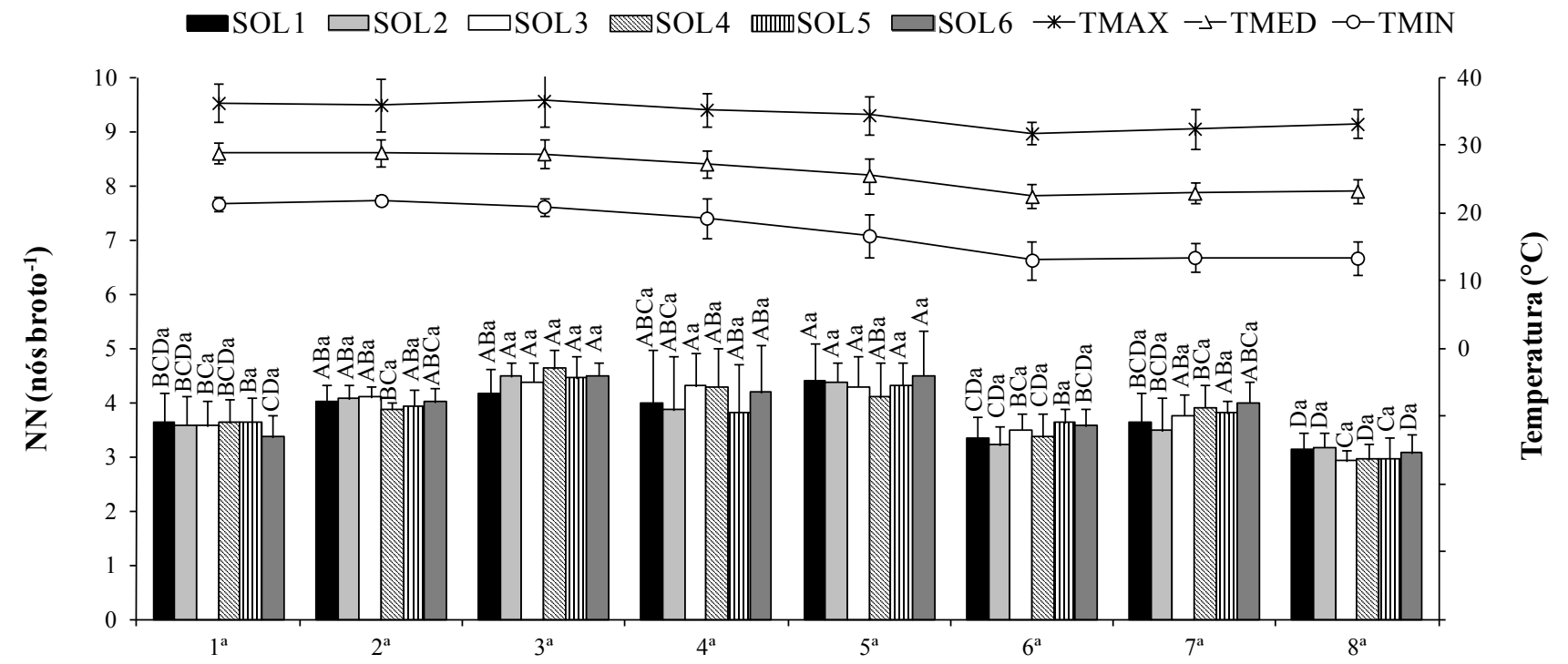

Coleta

Figura 5. Valores médios do número de nós por broto $(\mathrm{NN})$ de minicepas de Eucalyptus benthamii em relação à coleta de brotos e solução nutritiva. Médias seguidas por mesma letra maiúscula para a mesma solução nutritiva entre as coletas de brotos e, médias seguidas por mesma letra minúscula para a mesma coleta de brotos entre as soluções nutritivas não diferem significativamente pelo teste de Tukey ao nível de $5 \%$ de probabilidade de erro. Dados apresentados como: média \pm desvio padrão. 
A partir da $6^{\mathrm{a}}$ coleta de brotos houve redução significativa dos valores do NF e NN em relação às demais coletas efetuadas, sendo esse efeito associado com a redução da temperatura (máxima, média e mínima). $\mathrm{Na} 8^{\text {a }}$ coleta de brotos foram registrados os menores valores para o número de folhas por broto (Figura 4) e número de nós por broto (Figura 5).

De acordo com os dados mensurados podese observar que houve redução do IN até a $4^{\mathrm{a}}$ coleta de brotos, independente do clone avaliado (Figura 6). Contudo, a partir da $5^{\mathrm{a}}$ coleta de brotos houve aumento do IN, o que denota aumento do comprimento dos brotos. Os clones BP101 e BP120 apresentaram brotos com comprimento variando de 1,4 a $2,8 \mathrm{~cm}$ e o clone BP118, de 1,3 a $2,6 \mathrm{~cm}$ (Figura 6).

Ao considerar a variação da produção de miniestacas em relação ao clone e solução nutritiva, verifica-se que os clones BP101, BP118 e BP120 não apresentaram diferença significativa em relação às soluções $\mathrm{S} 3, \mathrm{~S} 4, \mathrm{~S} 5$ e $\mathrm{S} 6$, as quais corresponderam aos maiores valores médios (Figura 7). Contudo, ao considerar os clones BP101 e
BP118, pode-se observar que somente as soluções S1 e S2 (menores valores médios) apresentaram diferença significativa do NM em relação à solução S6 (maior valor médio). O clone BP120 apresentou diferença significativa da produção de miniestacas entre as soluções nutritivas S1 e S2 (menor valor médio) em relação à solução S5 (maior valor médio) (Figura 7).

Em termos gerais, a produção de miniestacas para o clone BP101 variou de 7.936,83 $\mathrm{m}^{-2}$ ano $^{-1}$ (solução S1) a $10.052,74 \mathrm{~m}^{-2}$ ano $^{-1}$ (solução S6), o clone BP118 variou de $7.579,98 \mathrm{~m}^{-2}$ ano $^{-1}$ (solução S2) a 10.243,16 m-2 ano ${ }^{-1}$ (solução S6) e o clone BP120 variou de 7.276,48 $\mathrm{m}^{-2} \mathrm{ano}^{-1}$ (solução S2) a 9.196,18 $\mathrm{m}^{-2}$ ano ${ }^{-1}$ (solução S5) (Figura 7).

A menor produção de miniestacas foi registrada na $1^{\mathrm{a}}$ coleta de brotos das minicepas, não sendo observada diferença significativa entre as soluções nutritivas. $\mathrm{Na}$ $5^{\text {a }}$ coleta de brotos houve diferença significativa da produção de miniestacas (NM) das minicepas que foram fertirrigadas com as soluções nutritivas S1 e S2 (ambas apresentando os menores valores médios) em relação à solução S6 (maior valor médio) (Figura 8).

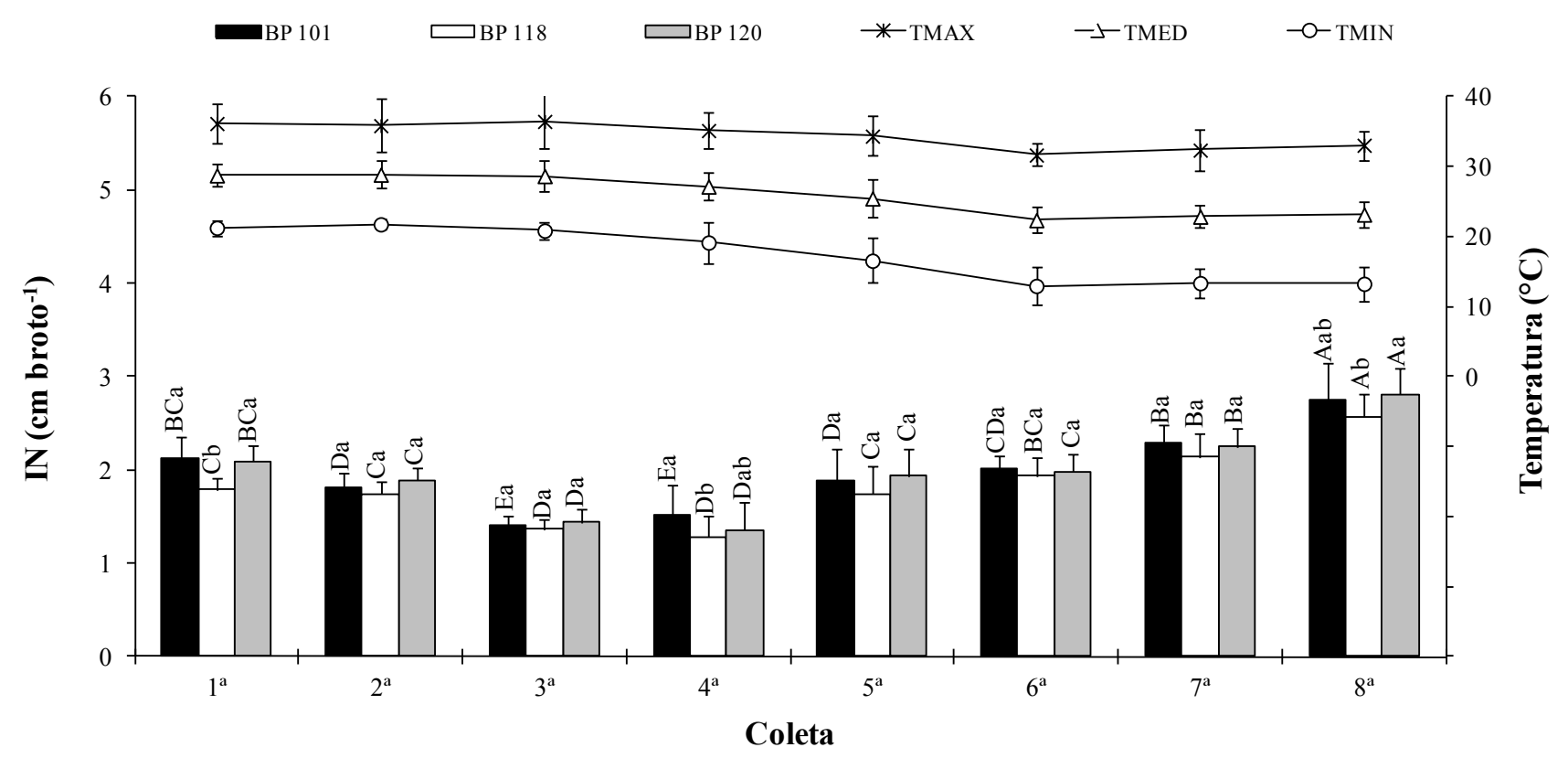

Figura 6. Valores médios do intervalo de entrenós por broto (IN) de minicepas de Eucalyptus benthamii em relação ao clone e coleta de brotos. Médias seguidas por mesma letra maiúscula para o mesmo clone entre as coletas de brotos e, médias seguidas por mesma letra minúscula para a mesma coleta de brotos entre os clones não diferem significativamente pelo teste de Tukey ao nível de 5\% de probabilidade de erro. Dados apresentados como: média \pm desvio padrão. 


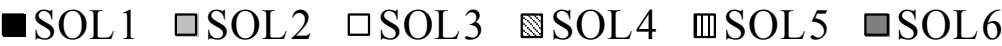

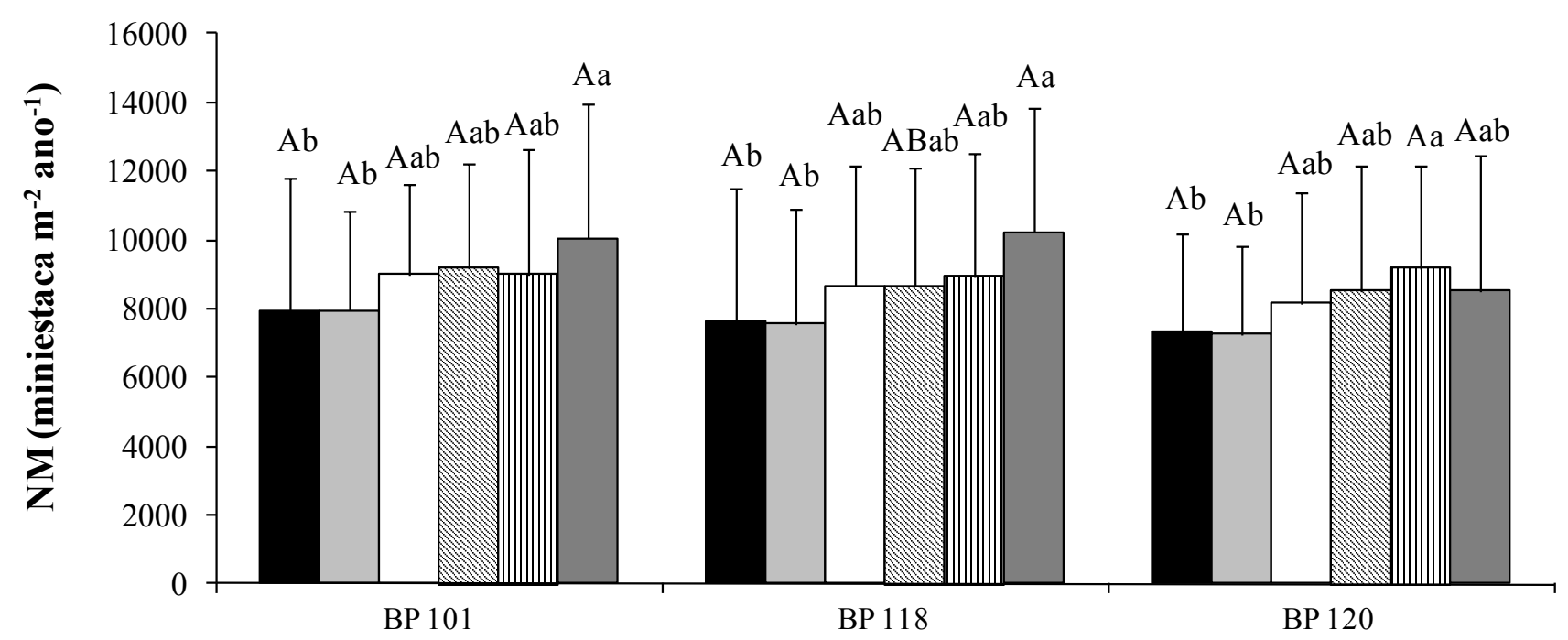

\section{Clone}

Figura 7. Valores médios do número de miniestacas $\left(\mathrm{NM} \mathrm{m}^{-2}\right.$ ano $\left.^{-1}\right)$ de minicepas de Eucalyptus benthamii em relação ao clone e solução nutritiva na $8^{\mathrm{a}}$ coleta de brotos. Médias seguidas por mesma letra maiúscula para a mesma solução nutritiva entre os clones e, médias seguidas por mesma letra minúscula para o mesmo clone entre as soluções nutritivas não diferem significativamente pelo teste de Tukey ao nível de $5 \%$ de probabilidade de erro. Dados apresentados como: média \pm desvio padrão.

Efeito semelhante ocorreu durante a $7^{\mathrm{a}}$ coleta de brotos, onde o NM apresentou diferença significativa das soluções S1 e S2 (menor produção) em relação às soluções S3, S4,

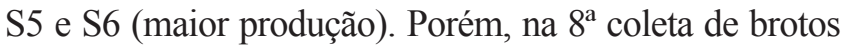
não foi constatada diferença significativa do $\mathrm{NM}$ entre as soluções nutritivas, apesar de existir uma tendência dos maiores valores médios de produção corresponderem às soluções nutritivas S5 e S6 (Figura 8).

Pela análise da Matriz de Correlação de Pearson verificase que existiu correlação significativa das temperaturas do ar (máximas, médias e mínimas) com o comprimento de broto (correlação negativa), número de folhas (correlação positiva), número de nós (correlação positiva) e intervalo de entrenós (correlação negativa) (Tabela 3). A sobrevivência de minicepas e a produção de miniestacas não apresentaram correlação significativa com os dados das temperaturas do ar da casa de vegetação que continha o minijardim clonal de Eucalyptus benthamii (Tabela 3).

A sobrevivência de minicepas também não apresentou correlação significativa com as demais variáveis biométricas mensuradas (número de miniestacas , comprimento de broto, número de folhas, número de nós e intervalo de entrenós). Além disso, o número de miniestacas apresentou correlação significativa com o número de folhas (correlação positiva) e número de nós (correlação positiva) (Tabela 3).

Em termos gerais, pode-se observar que as médias dos valores das temperaturas do ar máximas, médias e mínimas da casa de vegetação influenciaram significativamente as características de crescimento do $\mathrm{CB}, \mathrm{NF}, \mathrm{NN}$ e IN, denotando o forte efeito da variação da temperatura (condicionada pela sazonalidade) dentro da casa de vegetação em relação à miniestaquia de Eucalyptus benthamii, a qual influenciou a produção de miniestacas, principalmente em termos qualitativos, ao longo do ano (Tabela 3).

Em relação ao sintoma de deficiência nutricional, verificou-se intensa clorose com a presença de nervuras salientes (Figura 9 A-D e H-J), deformação e redução do tamanho das folhas, mortalidade do meristema apical seguido de superbrotamento (Figura 9 C-D), necrose localizada no centro da folha (Figura $9 \mathrm{E}$ ), estiolamento dos brotos (Figura $9 \mathrm{~F}$ ) e engrossamento da base do broto (Figura $9 \mathrm{G}$ ) nas minicepas submetidas às soluções $\mathrm{S} 1$ (omissão de Zn e B) e S2 (omissão de B) (Figura 9 A-J) a partir da $5^{\mathrm{a}}$ coleta de brotos. 


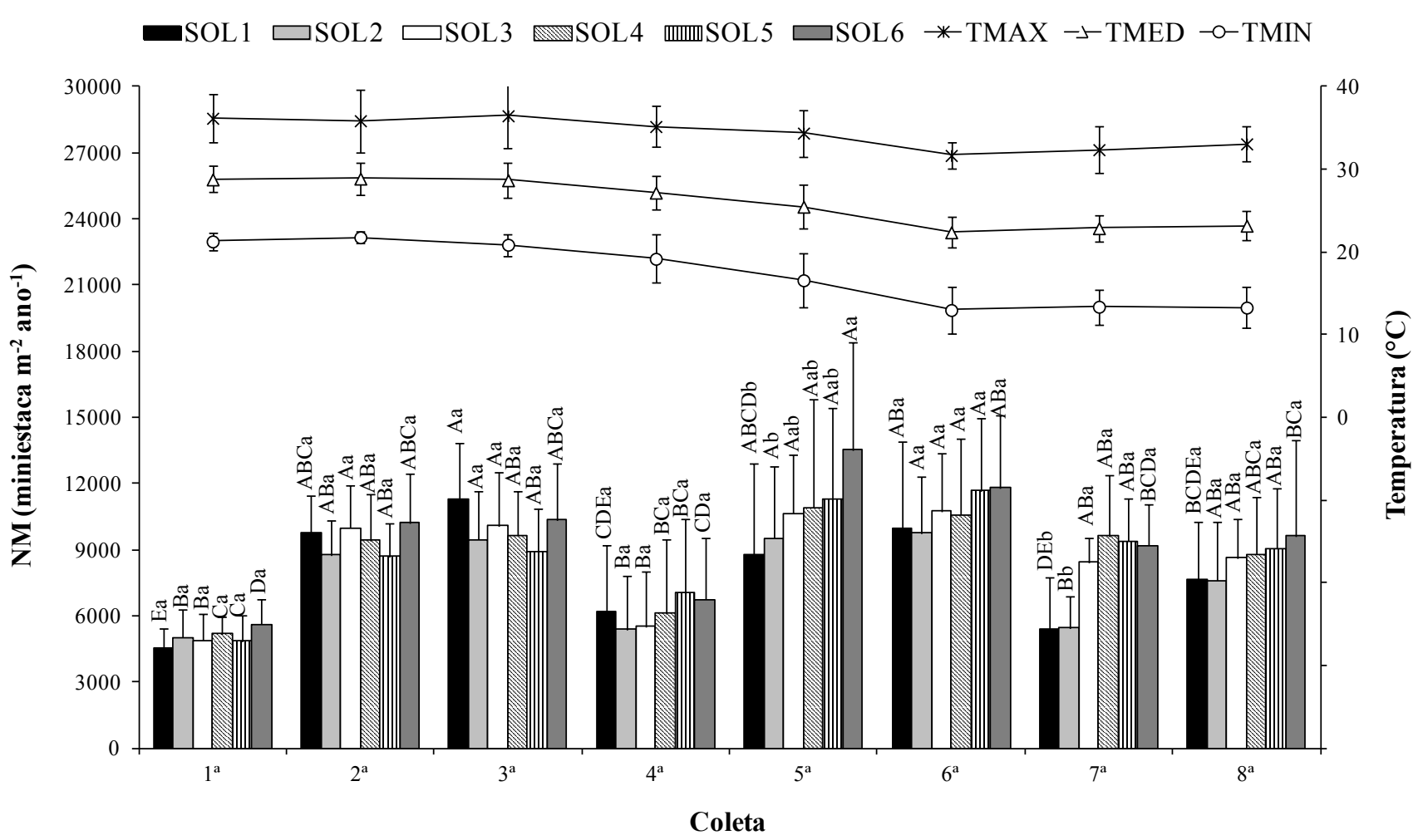

Figura 8. Valores médios do número de miniestacas $\left(\mathrm{NM} \mathrm{m}^{-2}\right.$ ano $\left.^{-1}\right)$ de minicepas de Eucalyptus benthamii em relação a coleta de brotos e solução nutritiva. Médias seguidas por mesma letra maiúscula para a mesma solução nutritiva entre as coletas de brotos e, médias seguidas por mesma letra minúscula para a mesma coleta de brotos entre as soluções nutritivas não diferem significativamente pelo teste de Tukey ao nível de $5 \%$ de probabilidade de erro. Dados apresentados como: média \pm desvio padrão.

Tabela 3. Matriz correlação de Pearson para a média das temperaturas do ar máximas (TMAX), temperaturas médias (TMED), temperaturas mínimas (TMIN), sobrevivência de minicepas (SOB), número de miniestacas $\left(\mathrm{NM} \mathrm{m}^{-2}\right.$ ano $\left.{ }^{-1}\right)$, comprimento de broto $(\mathrm{CB})$, número de folhas por broto $(\mathrm{NF})$, número de nós por broto $(\mathrm{NN})$ e intervalo de entrenós $(\mathrm{IN})$ de minicepas de Eucalyptus benthamii ao longo de 316 dias de coletas sucessivas de brotos.

\begin{tabular}{|c|c|c|c|c|c|c|c|c|c|}
\hline Variável & TMAX & TMED & TMIN & SOB & NM & CB & $\mathrm{NF}$ & NN & IN \\
\hline TMAX & 1 & & & & & & & & \\
\hline TMED & $0,99^{* *}$ & 1 & & & & & & & \\
\hline TMIN & $0,97^{* *}$ & $0,99^{* *}$ & 1 & & & & & & \\
\hline SOB & $0,17^{\mathrm{ns}}$ & $0,18^{\mathrm{ns}}$ & $0,19^{\mathrm{ns}}$ & 1 & & & & & \\
\hline $\mathrm{NM}$ & $-0,12^{\mathrm{ns}}$ & $-0,12^{\mathrm{ns}}$ & $-0,12^{\mathrm{ns}}$ & $0,19^{\mathrm{ns}}$ & 1 & & & & \\
\hline $\mathrm{CB}$ & $-0,25^{*}$ & $-0,28^{*}$ & $-0,30^{*}$ & $-0,07^{\mathrm{ns}}$ & $0,17^{\mathrm{ns}}$ & 1 & & & \\
\hline $\mathrm{NF}$ & $0,36^{* *}$ & $0,37^{* *}$ & $0,36^{* *}$ & $0,14^{\mathrm{ns}}$ & $0,21^{*}$ & $0,30^{*}$ & 1 & & \\
\hline $\mathrm{NN}$ & $0,36^{* *}$ & $0,37^{* *}$ & $0,37^{* *}$ & $0,14^{\mathrm{ns}}$ & $0,21^{*}$ & $0,30^{*}$ & $0,99^{* *}$ & 1 & \\
\hline IN & $-0,49^{* *}$ & $-0,54^{* *}$ & $-0,55^{* *}$ & $-0,18^{\mathrm{ns}}$ & $0,01^{\mathrm{ns}}$ & $0,70^{* * *}$ & $-0,42^{* *}$ & $-0,42^{* *}$ & 1 \\
\hline
\end{tabular}

${ }^{\text {ns }}$ Valor não significativo ao nível de $5 \%$ de probabilidade de erro pelo teste $\mathrm{F} ;{ }^{*}$ e ${ }^{* *}$ Valor significativo ao nível de $5 \%$ e $1 \%$ de probabilidade de erro, respectivamente, pelo teste $\mathrm{F}$. 




Figura 9. Sintomas foliares de deficiência nutricional de B e/ ou Zn em minicepas de Eucalyptus benthamii cultivadas em sistema de minijardim clonal em vasos contendo areia. (A e B) clorose nas folhas mais jovens e redução do tamanho das folhas, com omissão de B e Zn (S1); (C e D) clorose nas folhas mais jovens com deformação e redução do tamanho das folhas, evidenciando superbrotamento, com omissão de B e Zn (S1) e B (S2); (E) detalhe do sintoma foliar típico da deficiência de B, solução S1 (omissão de Zn e B) e S2 (omissão de B); (F) detalhe do estiolamento dos brotos, com omissão de $\mathrm{Zn}$ e B (S1); (G) detalhe do engrossamento da base do broto, com omissão de B e Zn (S1) e B (S2); (H) detalhe da clorose com omissão de Zn e B (S1); (I e J) detalhe da clorose com omissão de B (S2).

\section{Discussão}

Em termos gerais, os valores da porcentagem de sobrevivência das minicepas de Eucalyptus benthamii até a $7^{\text {a }}$ coleta de brotos podem ser considerados elevados e adequados para a condução de minijardins clonais de Eucalyptus (Alfenas et al., 2004; Assis \& Mafia, 2007), denotando viabilidade das minicepas como fonte fornecedora de brotos durante o período experimental. Esse resultado corrobora as observações de Cunha et al. (2005), que também relataram elevada sobrevivência de minicepas de Eucalyptus benthamii em sistema de minijardim clonal (tubete e canaletão com areia).

Outros trabalhos reportam a ocorrência de elevadas porcentagens de sobrevivência de minicepas em minijardins clonais de Eucalyptus, sendo comuns valores superiores a 90\%. Brondani (2008) observou elevada porcentagem de sobrevivência $(>90 \%)$ de minicepas de Eucalyptus benthamii x Eucalyptus dunnii conduzidas em sistema de minijardim clonal durante 352 dias de sucessivas coletas de brotos (27 coletas), constatando longevidade das minicepas como fonte fornecedora de brotos. Resultados semelhantes também foram reportados para Eucalyptus spp. (Wendling, 1999) e Eucalyptus grandis (Titon et al., 2003; Wendling et al., 2003) reforçando as observações do presente estudo.

Contudo, ao considerar o aspecto nutricional, houve diferença significativa da sobrevivência de minicepas entre os genótipos e solução nutritiva na $8^{\text {a coleta de }}$ brotos, principalmente em relação à omissão de $\mathrm{B}$ (S1 e S2). O clone BP118 apresentou os maiores índices de sobrevivência de minicepas em relação aos clones BP101 e BP120, os quais foram mais sensíveis à omissão de B. Dessa forma, pode-se inferir que o clone BP118 apresentou maior adaptação ao tipo de manejo adotado para a condução do minijardim clonal em vaso com areia, tanto em termos de manejo de poda e variação nutricional de $\mathrm{Zn}$ e $\mathrm{B}$, quanto em relação às condições ambientais da casa de vegetação. Essa diferença de resposta entre materiais genéticos em relação às técnicas de propagação é enfatizada por Hartmann et al. (2011), sendo comum ser adotado um manejo específico no sistema de produção de miniestacas para cada clone (Alfenas et al., 2004; Assis \& Mafia, 2007).

Embora em outras condições experimentais, a diferença de comportamento entre genótipos de Eucalyptus quanto as concentrações de $\mathrm{Zn}$ ou $\mathrm{B}$ em solução nutritiva também foi relatada em diversos trabalhos (Silveira et al., 1998, 2000, 2002, 2004; Sgarbi et al., 1999; Barretto et al., 2007), considerando a essencialidade desses elementos para o metabolismo da planta (Sakya et al., 2002; Epstein \& Bloom, 2004; Malavolta, 2006; Cunha et al., 2009; Taiz \& Zeiger, 2009), o que compromete o crescimento e desenvolvimento do vegetal em condições de deficiência.

Em termos de miniestaquia, a deficiência de $\mathrm{Zn}$ ou $\mathrm{B}$ pode condicionar a adaptabilidade do genótipo ao sistema de produção no minijardim clonal, refletindo na capacidade da minicepa em produzir brotos aptos para serem submetidos ao enraizamento. Dessa forma, as soluções nutritivas devem ser ajustadas para os clones mais sensíveis à deficiência de um determinado nutriente, a fim de manter a produção de brotos em níveis adequados. Considerando esse aspecto, as soluções $\mathrm{S} 5$ (1 $\mathrm{mg} \mathrm{L}^{-1}$ de B e Zn) e S6 (2 mg L-1 de B e Zn) foram as mais adequadas para a sobrevivência de minicepas de Eucalyptus benthamii submetidas a sucessivas coletas de brotos. 
Ao considerar a qualidade do broto, a solução nutritiva influenciou o número de nós e o número de folhas emitidas pelas minicepas de Eucalyptus benthamii ao longo das sucessivas coletas de brotos, semelhante ao reportado para Eucalyptus grandis x Eucalyptus urophylla (Sgarbi et al., 1999; Silveira et al., 2002; Barretto et al., 2007), Eucalyptus citriodora (Silveira et al., 1998, 2000) e para Eucalyptus saligna e Eucalyptus grandis (Silveira et al., 2004), os quais foram sensíveis a omissão de B em solução nutritiva. Sgarbi et al. (1999) classificaram o B como um dos nutrientes que mais limitou o crescimento de Eucalyptus grandis $\mathrm{x}$ Eucalyptus urophylla, reduzindo o crescimento em altura e a produção de matéria seca, além de comprometer a sobrevivência das mudas.

O comprimento de broto e o intervalo de entrenós não apresentaram variação em relação à solução nutritiva, mas somente em relação à coleta de brotos e entre os genótipos de Eucalyptus benthamii, refletindo o efeito da sazonalidade na qualidade do broto produzido ao longo do ano. Esse efeito está de acordo com o relatado na literatura, em que a qualidade dos brotos está intimamente ligada aos fatores ambientais, como a luminosidade (Alfenas et al., 2004), temperatura do ar (Higashi et al., 2005) e fotoperíodo (Assis \& Mafia, 2007), os quais são condicionados pela sazonalidade (Cunha et al., 2009) e influenciam significativamente a produção e a qualidade de brotos ao longo do ano em diferentes condições de manejo. Além disso, pode-se verificar correlação dos dados da temperatura do ar com o comprimento de broto, número de folhas, número de nós e intervalo de entrenós (Tabela 3), reforçando as observações do presente estudo com Eucalyptus benthamii. Apesar da variação da qualidade, os brotos das minicepas apresentaram-se aptos para a confecção de miniestacas durante todo o ano, não ocorrendo perda de amostragem das unidades experimentais.

Outra característica biométrica que apresentou variação em relação à solução nutritiva, principalmente na omissão de B (S1 e S2), foi a produção de miniestacas das minicepas de Eucalyptus benthamii conduzidas em sistema de vasos. Geralmente, a produção de miniestacas em sistema de minijardim clonal de Eucalyptus oscila de acordo com as coletas ao longo do tempo, sendo comum a ocorrência de picos de produção seguidos de decréscimos, ou seja, efeito cíclico (Titon et al., 2003; Cunha et al., 2005, 2008). Esse efeito foi observado ao longo das coletas de brotos de miniestacas de Eucalyptus benthamii, o qual parece não seguir um comportamento constante de produção (elevada variância dentro e entre as coletas de brotos), semelhante ao observado por Wendling et al. (2003), Wendling \& Xavier (2003), Cunha et al. $(2005,2009)$ e Brondani (2008). Essa característica de comportamento está associada ao manejo de poda (Alfenas et al., 2004; Wendling et al., 2003), variações da temperatura (Brondani, 2008), fotoperíodo (Cunha et al., 2005, 2009), fatores genéticos (Wendling \& Xavier, 2003), intervalo entre coletas (Wendling et al., 2003), aspectos nutricionais (Titon et al., 2003; Higashi et al., 2005; Cunha et al., 2008; Rosa et al., 2009) e juvenilidade da minicepa (Wendling \& Xavier, 2003; Wendling et al., 2003), os quais afetam significativamente a produção de miniestacas ao longo do tempo.

Ao considerar a miniestaca apical como propágulo oriundo de minicepas manejadas em minijardim clonal foi verificada variação de 7.488 a $41.480 \mathrm{~m}^{-2}$ ano $^{-1}$ de miniestacas, sendo essa produção muito dependente do genótipo e do tipo de minijardim clonal (Alfenas et al., 2004). Dessa forma, pode-se inferir que os valores médios do número de miniestacas produzidas das minicepas de Eucalyptus benthamii que foram fertirrigadas com as soluções $\mathrm{S} 3\left(0,5 \mathrm{mg} \mathrm{L}^{-1}\right.$ de B), S4 $\left(0,5 \mathrm{mg} \mathrm{L}^{-1}\right.$ de $\mathrm{Zn}$ e B), S5 (1,0 mg L-1 de Zn e B) e S6 (2,0 mg L-1 de Zn e B) estão adequados em relação aos padrões registrados na literatura para Eucalyptus. Contudo, as soluções S1 (omissão de Zn e B) e S2 (omissão de B) estão próximas ao limite inferior de produção, podendo ser considerados reduzidos, o que poderia comprometer o padrão da produção de brotos com o passar do tempo. Apesar da não constatação de diferença significativa para todas as coletas de brotos, em termos médios, a omissão de $\mathrm{B}$ na solução nutritiva representou perdas de até $13,3 \%$ da produção de miniestacas $\left(\mathrm{m}^{-2}\right.$ ano $\left.{ }^{-1}\right)$, denotando a importância desse nutriente para o tipo de sistema empregado.

A omissão de $\mathrm{Zn}$ na presença de $0,5 \mathrm{mg} \mathrm{L}^{-1}$ de $\mathrm{B}$ na forma como foi aplicada na solução nutritiva (S3), não influenciou significativamente a produção de miniestacas $\left(\mathrm{m}^{-2}\right.$ ano $\left.^{-1}\right)$ de Eucalyptus benthamii, assemelhando-se aos valores das soluções $\mathrm{S} 4\left(0,5 \mathrm{mg} \mathrm{L}^{-1}\right.$ de $\mathrm{Zn} \mathrm{e} \mathrm{B),}$ S5 (1,0 mg L ${ }^{-1}$ de Zn e B) e S6 (2,0 mg L ${ }^{-1}$ de Zn e B). Sgarbi et al. (1999) também não verificaram influência significativa das características de crescimento em Eucalyptus grandis x Eucalyptus urophylla ao omitir $\mathrm{Zn}$ em solução nutritiva. O Zn é classificado como 
traço, sendo requerido em baixa concentração pelas plantas (Malavolta, 2006) e, por apresentar intermediária redistribuição entre os tecidos vegetais (Taiz \& Zeiger, 2009), as minicepas podem não ter apresentado sintomas de deficiência dentro do período experimental. Outro aspecto a ser considerado, refere-se ao teor de $\mathrm{Zn}$ existente na água utilizada para a composição da solução nutritiva, o qual foi de $0,01 \mathrm{mg} \mathrm{L}^{-1}$. Provavelmente, as irrigações diárias (variando de $600 \mathrm{~mL}$ a $1.000 \mathrm{~mL}$ por vaso de acordo com a época do ano) e as lavagens semanais para reduzir a salinização no substrato podem ter suprido a disponibilidade de $\mathrm{Zn}$ para as minicepas, mesmo que esse elemento tenha apresentado baixa concentração na água, caracterizando efeito contaminante no tratamento isento de $\mathrm{Zn}$. Esses fatores podem ter influenciado para a ausência nas folhas de sintomas de deficiência nutricional de Zn (Dell et al., 1995), bem como alterações significativas nas características de crescimento das minicepas de Eucalyptus benthamii. No caso de haver novas pesquisas com o mesmo tipo de sistema de manejo adotado no presente estudo, esses fatores de variação deverão ser considerados e controlados com maior rigor a fim de estudar o efeito do $\mathrm{Zn}$ nas características de crescimento de minicepas, sobretudo em relação ao tipo de substrato e controle da pureza da água de irrigação e fertirrigação.

A temperatura apresenta papel fundamental para a atividade metabólica do vegetal (Taiz \& Zeiger, 2009), influenciando inúmeros fatores, como a disponibilidade e absorção de nutrientes (Malavolta, 2006), velocidade de crescimento (Hartmann et al., 2011), ativação e inativação de enzimas (Epstein \& Bloom, 2004), os quais interferem no crescimento e desenvolvimento do vegetal. $\mathrm{O}$ efeito da temperatura na miniestaquia de Eucalyptus foi reportado por Cunha et al. (2009) e está muito condicionado à disposição geográfica, altitude e variações da sazonalidade ao longo do ano (Alfenas et al., 2004; Assis \& Mafia, 2007; Hartmann et al., 2011). A influência da temperatura na técnica de miniestaquia também foi confirmada no presente estudo ao verificar correlação significativa com as características de crescimento (comprimento de broto, número de folhas, número de nós e intervalo de entrenós) das minicepas de Eucalyptus benthamii (Tabela 3), as quais condicionaram em grande parte as respostas obtidas em termos de qualidade dos brotos.

Em relação à omissão de $\mathrm{Zn}$ e $\mathrm{B}$ na solução nutritiva, os sintomas de deficiência nutricional de B foram caracterizados como os mais frequentes nas minicepas de Eucalyptus benthamii, denotando a eficiência da metodologia aplicada para estudar o efeito do B. Porém o Zn não foi afetado de acordo com as soluções nutritivas, sendo os teores foliares classificados como adequados em todos os tratamentos, assemelhando-se ao reportado por Sgarbi et al. (1999) para Eucalyptus grandis x Eucalyptus urophylla.

De acordo com a literatura, os sintomas mais comuns de deficiência de B em Eucalyptus são caracterizados pela: $(i)$ morte dos meristemas apicais seguida de superbrotamento das gemas laterais devido a perda da dominância apical, (ii) folhas novas de tamanho reduzido, deformadas, encarquilhadas e coriáceas, (iii) clorose marginal e (iv) presença de nervuras salientes nas folhas medianas intermediárias (Sgarbi et al., 1999; Silveira et al., 2000; Silveira et al., 2002; Silveira et al., 1998). Esses sintomas foram registrados nas minicepas submetidas ao tratamento com as soluções S1 (omissão de Zn e B) e S2 (omissão

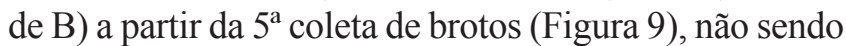
verificados para as demais soluções nutritivas. Esse fato indica que a deficiência de B foi mais pronunciada e refletiu em alterações morfofisiológicas das minicepas de Eucalyptus benthamii.

\section{Conclusões}

A sobrevivência das minicepas variou significativamente em relação ao clone e solução nutritiva e, de acordo com a coleta de brotos. O clone BP118 apresentou a maior porcentagem de sobrevivência de minicepas em relação aos demais clones avaliados.

A produção de miniestacas variou significativamente conforme a coleta de brotos, solução nutritiva e material genético.

As soluções S5 (1,0 $\mathrm{mg} \mathrm{L}^{-1}$ de Zn e B) e S6 (2,0 mg $\mathrm{L}^{-1}$ de $\mathrm{Zn}$ e B) favoreceram a produção de miniestacas, a qualidade do broto e a sobrevivência de minicepas, sendo recomendadas para a miniestaquia de Eucalyptus benthamii em sistema de vaso.

\section{Agradecimentos}

À FAPESP (Fundação de Amparo à Pesquisa do Estado de São Paulo) e CAPES (Coordenação de Aperfeiçoamento de Pessoal de Nível Superior) pelo suporte financeiro e, à Planflora pela disponibilização dos materiais genéticos de Eucalyptus benthamii. 


\section{Referências}

ALFENAS, A. C.; ZAUZA, E. A. V.; MAFIA, R. G.; ASSIS, T. F. Clonagem e doenças do eucalipto. Viçosa, MG: UFV, 2004. 442 p.

ALMEIDA, F. D.; XAVIER, A.; DIAS, J. M. M.; PAIVA, H. N. Eficiência das auxinas (AIB e ANA) no enraizamento de miniestacas de clones de Eucalyptus cloeziana F. Muell. Revista Árvore, Viçosa, MG, v. 31, n. 3, p. 455-463, 2007. DOI: 10.1590/S010067622007000300011 .

ASSIS, T. F.; MAFIA, R. G. Hibridação e clonagem. In: BORÉM, A. (Ed.). Biotecnologia florestal. Viçosa, MG: Suprema, 2007. p. 93-121.

BARRETTO, V. C. M.; VALERI, S. V.; SILVEIRA, R. L. V. A.; TAKAHASHI, E. N. Eficiência de uso de boro no crescimento de clones de eucalipto em vasos. Scientia Forestalis, Piracicaba, SP, n. 76, p. 21-33, 2007.

BRONDANI, G. E. Miniestaquia e micropropagação de Eucalyptus benthamii Maiden \& Cambage x Eucalyptus dunnii Maiden. 2008. 118 f. Dissertação (Mestrado em Engenharia Florestal) - Universidade Federal do Paraná, Curitiba.

BRONDANI, G. E.; GONÇALVES, A. N.; ALMEIDA, M. Determinação do tempo ótimo de enraizamento para miniestacas de Eucalyptus benthamii Maiden \& Cambage. In: REUNIÓN ARGENTINA DE FISIOLOGÍA VEGETAL, 28., 2010, La Plata. Libro de Resúmenes... La Plata: Asociación Sociedad Argentina de Fisiología Vegetal, 2010a. p. 194.

BRONDANI, G.E.; GROSSI, F.; WENDLING, I.; DUTRA, L.F.; ARAUJO, M.A. Aplicação de IBA para o enraizamento de miniestacas de Eucalyptus benthamii Maiden \& Cambage x Eucalyptus dunnii Maiden. Acta Scientiarum. Agronomy, Maringá, v. 32, n. 4, p. 667-674, 2010b. DOI: 10.4025/actasciagron.v32i4.4879.

BRONDANI, G. E.; WENDLING, I.; GROSSI, F.; DUTRA, L. F.; ARAUJO, M. A. Miniestaquia de Eucalyptus benthamii $\times$ Eucalyptus dunnii: ( II ) sobrevivência e enraizamento de miniestacas em função das coletas e estações do ano. Ciência Florestal, Santa Maria, RS, v. 20, n. 3, p. 453-465, 2010c.

CUNHA, A. C. M. C. M.; PAIVA, H. N.; BARROS, N. F.; LEITE, H. G.; LEITE, F. P. Relação do estado nutricional de miniestacas com o número de miniestacas de eucalipto. Scientia Forestalis, Piracicaba, SP, v. 36, n. 79, p. 203-213, 2008.

CUNHA, A. C. M. C. M.; PAIVA, H. N.; LEITE, H. G.; BARROS, N. F.; LEITE, F. P. Relações entre variáveis climáticas com produção e enraizamento de miniestacas de eucalipto. Revista Árvore, Viçosa, MG, v. 33,n. 2,p. 195-203, 2009. DOI: 10.1590/S0100-67622009000200001

CUNHA, A. C. M. C. M.; WENDLING, I.; SOUZA JUNIOR, L. Produtividade e sobrevivência de minicepas de Eucalyptus benthamii Maiden et Cambage em sistema de hidroponia e em tubete. Ciência Florestal, Santa Maria, RS, v. 15, n. 3, p. 307-310, 2005.

DELL, B.; MALAJCZUK, N.; GROVE, T. S. Nutrient disorders in plantation eucalypts. Canberra: ACIAR, 1995. 110 p. (ACIAR Monograph, 31).

ELDRIDGE, K.; DAVIDSON, J.; HARDWIID, C.; VAN WYK, G. Mass vegetative propagation. In: ELDRIDGE, K.; DAVIDSON, J.; HARDWIID, C.; VAN WYK, G. Eucalypt domestication and breeding. Oxford: Clarendon Press, 1994. p. 228-246.
EPSTEIN, E.; BLOOM, A. J. Nutrição mineral de plantas: princípios e perspectivas. Londrina: Planta, 2004. 403 p.

GRAÇA, M. E. C.; SHIMIZU, J. Y.; TAVARES, F. R. Capacidade de rebrota e de enraizamento de Eucalyptus benthamii. Boletim de Pesquisa Florestal, Colombo, n. 39, p. 135-138, 1999.

HARTMANN, H. T.; KESTER, D. E.; DAVIES JR, F. T.; GENEVE, R. L. Plant propagation: principles and practices. 8th ed. São Paulo: Prentice-Hall, 2011. 915 p.

HIGASHI, E. N.; SILVEIRA, R. L. V. A.; GONÇALVES, A. N. Monitoramento nutricional e fertilização em macro, mini e microjardim clonal de Eucalyptus. In: GONÇALVES, J. L. M.; BENEDETTI, V. (Eds.). Nutrição e fertilização florestal. Piracicaba, SP: IPEF, 2005. p. 191-217.

ISHIHARA, A.; MATSUDA, F.; MIYAGAWA, H.; WAKASA, K. Metabolomics for metabolically manipulated plants: effects of tryptophan overproduction. Metabolomics, Boston, v. 3, n. 3, p. 319-334, 2007. DOI: 10.1007/s11306-007-0072-4

JOVANOVIC, T.; BOOTH, T. H. Improved species climatic profiles. Australia: Union Offset Printing, Joint Venture Agroforestry Program, Rural Industries Research and Development Corporation, 2002. 68 p.

KRATZ, D.; WENDLING, I.; BRONDANI, G. E.; DUTRA, L. F. Propagação assexuada de Cupressus lusitanica. Pesquisa Florestal Brasileira, Colombo, v. 30, n. 62, p. 161-164, 2010. DOI: 10.4336/2010.pfb.30.62.161

LUDWIG-MÜLLER, J. Indole-3-butyric acid in plant growth and development. Plant Growth Regulation, Dordrecht, v. 32, n. 2/3, p. 219-230, 2000. DOI: 10.1023/A:1010746806891

MALAVOLTA, E. Manual de nutrição mineral de plantas. São Paulo: Agronômica Ceres, 2006. 638 p.

MALTA, M. R.; FURTINI NETO, A. E.; ALVES, J. D.; GUIMARÃES, P. T. G. Efeito da aplicação de zinco via foliar na síntese de triptofano, aminoácidos e proteínas solúveis em mudas de cafeeiro. Brazilian Journal of Plant Physiology, Londrina, v. 14, n. 1, p. 31-37, 2002. DOI: $10.1590 /$ S1677-04202002000100004

MÜLLER, A.; DÜCHTING, P.; WEILER, E. W. A multiplex GC-MS/ MS technique for the sensitive and quantitative single-run analysis of acidic phytohormones and related compounds, and its application to Arabidopsis thaliana. Planta, Berlin, v. 216, n. 1, p. 44-56, 2002. DOI: 10.1007/s00425-002-0866-6

MÜLLER, A.; WEILER., E. W. IAA-synthase, an enzyme complex from Arabidopsis thaliana catalyzing the formation of indole-3-acetic acid from (S)-tryptophan. Biological Chemistry, Berlin, v. 381, n. 8, p. 679-686, 2000. DOI: 10.1515/BC.2000.088

MUJU, L.; ARNOLD, R.; BOHAI, L.; MINSHENG, Y. Selection of cold-tolerant eucalypts for Hunan Province. In: TURNBULL, J. W. (Ed.). Eucalypts in Asia: proceedings of a international conference held in Zhanjiang, Guangdong, people's Republic of China. Canberra: Elect Printing, 2003. p. 107-116. (ACIAR. Proceedings, 111).

PALUDZYSZYN FILHO, E.; SANTOS, P. E. T.; FERREIRA, C. A. Eucaliptos indicados para plantio no Estado do Paraná. Colombo: Embrapa Florestas, 2006. 45 p. (EMBRAPA. Documentos, 129).

Pesq. flor. bras., Colombo, v. 32, n. 70, p. 151-164, abr./jun. 2012 
POLLMANN, S.; DÜCHTING, P.; WEILER, E. W. Tryptophandependent indole-3-acetic acid biosynthesis by 'IAA-synthase' proceeds via indole-3-acetamide. Phytochemistry, New York, v. 70, n. 4, p. 523-531, 2009. DOI: 10.1016/j.phytochem.2009.01.021

ROSA, L. S.; WENDLING, I.; GROSSI, F.; REISSMANN, C. B. Efeito da dose de nitrogênio e de formulações de substratos na miniestaquia de Eucalyptus dunnii Maiden. Revista Árvore, Viçosa, MG, v. 33, n. 6, p. 1025-1035, 2009. DOI: 10.1590/S0100-67622009000600005

RUBIO, V.; BUSTOS, R.; IRIGOYEN, M. L.; CARDONA-LÓPEZ, X.; ROJAS-TRIANA, M.; PAZ-ARES, J. Plant hormones and nutrient signaling. Plant Molecular Biology, Dordrecht, v. 69, n. 4, p. 361-373, 2009. DOI: $10.1007 / \mathrm{s} 11103-008-9380-\mathrm{y}$

SAKYA, A.T.; DELL, B.; HUANG, L. Boron requirements for Eucalyptus globulus seedlings. Plant and Soil, The Hague, v. 246, n. 1, p. 87-95, 2002. DOI: 10.1023/A:1021589029492

SGARBI, F.; SILVEIRA, R. L. V. A.; TAKAHASHI, E. N.; CAMARGO, M. A. F. Crescimento e produção de biomassa de clone de Eucalyptus grandis x Eucalyptus urophylla em condições de deficiência de macronutrientes, B e Zn. Scientia Forestalis, Piracicaba, SP, n. 56, p. 69-82, 1999.

SILVEIRA, R. L. V. A.; GONÇALVES, A. N.; KRÜGNER, T. L. Estado nutricional de Eucalyptus citriodora Hook cultivado sob diferentes doses de boro e sua relação com a agressividade de Botryosphaeria ribis. Scientia Forestalis, Piracicaba, SP, n. 53, p. 57-70, 1998.

SILVEIRA, R.L.V.A.; MOREIRA, A.; HIGASHI, E.N. Crescimento e sobrevivência de mudas de eucalipto sob doses de boro cultivadas em condições de viveiro e de campo. Ciência eAgrotecnologia, Lavras, MG, v. 28, n. 2, p. 366-371, 2004. DOI: 10.1590/S1413-70542004000200017

SILVEIRA, R. L. V. A.; MOREIRA, A.; TAKASHI, E. N.; SGARBI, F.; BRANCO, E. F. Sintomas de deficiência de macronutrientes e de boro em clones híbridos de Eucalyptus grandis com Eucalyptus urophylla. Cerne, Lavras, MG, v. 8, n. 2, p. 107-116, 2002.
SILVEIRA, R. L. V.A.; TAKAHASHI, E. N.; SGARBI, F.; CAMARGO, M. A. F.; MOREIRA, A. Crescimento e estado nutricional de brotações de Eucalyptus citriodora sob doses de boro em solução nutritiva. Scientia Forestalis, Piracicaba, SP, n. 57, p. 53-67, 2000.

SOUZA, A. V.; PEREIRA, A. M. S. Enraizamento de plantas cultivadas in vitro. Revista Brasileira de Plantas Medicinais, Botucatu, v. 9, n. 4, p. 103-117, 2007.

TAIZ, L.; ZEIGER, E. Fisiologia vegetal. 4. ed. Porto Alegre: Artmed, 2009. $848 \mathrm{p}$.

TITON, M.; XAVIER, A.; REIS, G. G.; OTONI, W. C. Eficiência das minicepas e microcepas na produção de propágulos de clones de Eucalyptus grandis. Revista Árvore, Viçosa, MG, v. 27, n. 5, p. 619-625, 2003.

WENDLING, I. Propagação clonal de híbridos de Eucalyptus spp. por miniestaquia. 1999. 70 f. Dissertação (Mestrado em Ciência Florestal) Universidade Federal de Viçosa, Viçosa, MG.

WENDLING, I.; XAVIER, A. Influência do ácido indolbutírico e da miniestaquia seriada no enraizamento e vigor de miniestacas de clones de Eucalyptus grandis. Revista Árvore, Viçosa, MG, v. 29, n. 6, p. 921-930, 2005.

WENDLING, I.; XAVIER, A. Miniestaquia seriada no rejuvenescimento de clones de Eucalyptus. Pesquisa Agropecuária Brasileira, Brasília, DF, v. 38, n. 4, p. 475-480, 2003. DOI: 10.1590/S0100-204X2003000400005

WENDLING, I.; XAVIER, A.; PAIVA, H.N. Influência da miniestaquia seriada no vigor de minicepas de clones de Eucalyptus grandis. Revista Árvore, Viçosa, MG, v. 27, n. 5, p. 611-618, 2003. DOI: 10.1590/S010067622003000500003

WIT ONDAS, H. W.; BRONDANI, G. E.; FIGUEIREDO, C. R. F.; ALMEIDA, C. V.; ALMEIDA, M. Exposição ao frio e análise histológica no enraizamento de miniestacas de Eucalyptus benthamii. In: SIMPÓSIO INTERNACIONAL DE INICIAÇÃO CIENTÍFICA DA UNIVERSIDADE DE SÃO PAULO, 17., 2009, Pirassununga. Anais... Pirassununga: FMVZ, 2009. 